\title{
Antibody-enabled antimicrobial nanocapsules for
}

\section{selective elimination of Staphylococcus aureus}

Kristina Ivanova, ${ }^{1}$ Aleksandra Ivanova, ${ }^{1}$ Eva Ramon, ${ }^{1}$ Javier Hoyo, ${ }^{1}$ Susana Sanchez-Gomez, ${ }^{2}$

Tzanko Tzanov ${ }^{1^{*}}$

1) Grup de Biotecnologia Molecular i Industrial, Department of Chemical Engineering,

Universitat Politècnica de Catalunya, Rambla Sant Nebridi 22, 08222, Terrasa, Spain

2) Bionanoplus S.L., Pol. Mocholi, Plaza Cein 5, nave B14, 31110 Noain, Spain

\section{KEYWORDS}

S. aureus, antibiotic resistance, essential oil, zein nanocapsules, targeting antibody, selective antibacterial activity 


\section{ABSTRACT}

Targeted bactericide nanosystems hold significant promise to improve the efficacy of existing antimicrobials for treatment of severe bacterial infections, minimizing the side effects and lowering the risk of antibiotic resistance occurrence. In this work, we developed antibody functionalized nanocapsules (NCs) containing antibacterial essential oil (EO) for selective and effective eradication of Staphylococcus aureus. Antibacterial EO NCs were produced via selfassembling nanoencapsulation in the plant-derived protein zein. The obtained EO NCs were decorated with aminocellulose to provide more reactive surface groups for carboxyl-to-amine immobilization of a specific against $S$. aureus antibody. The antibody-enabled EO NCs (Ab@EO NCs) demonstrated 2-fold higher bactericidal efficacy against the targeted bacterium compared to the pristine $\mathrm{EO} \mathrm{NCs}$ at the same concentrations. The improved antibacterial effect of the Ab@EO NCs towards $S$. aureus was also confirmed in a real time assay by monitoring bacterial cells elimination using a quartz crystal microbalance. Furthermore, the Ab@EO selectively decreased the load and changed the cell morphology of the targeted S. aureus in a mixed inoculum with nontargeted $P$. aeruginosa. Applying the nanoformulated actives to an in vitro co-culture model of the bacteria and skin fibroblasts resulted in suppression of $S$. aureus growth, while preserving the human cells viability. The novel antibody-enabled antibacterial NCs showed potential to improve the treatment efficacy of staphylococcal infections, minimally affecting the beneficial microbiome and human cells. 


\section{INTRODUCTION}

Antimicrobial resistance (AMR) has emerged as a major public health issue of the 21 st century that threatens the effective prevention and treatment of bacterial infections. ${ }^{1}$ Resistance development is a natural response of bacteria to survive in hostile environments and it is significantly accelerated by the mis- and overuse of antibiotics. ${ }^{2}$ Antibiotic resistant bacteria in community and hospital settings can be easily transmitted by direct contact between infected and susceptible person, or indirectly upon contact with contaminated surfaces. ${ }^{3}$ AMR infections are the main reason for the increased morbidity and mortality in the healthcare facilities, longer hospital stays and elevated financial burden worldwide. ${ }^{4}$ Assessment of the future impact of AMR predicts almost 10 million deaths annually worldwide by 2050 if new antibiotic alternatives are not urgently developed. ${ }^{5,6}$ However, the high production costs and long approval time hamper the engineering of new antibacterials, considering the rapid emergence of new resistant bacterial strains.

Nano-antibacterials have gained considerable attention for overcoming AMR due to their unique physico-chemical properties. ${ }^{7}$ Nanomaterials have been used as delivery platforms for antibacterial agents such as antibiotics, ${ }^{8}$ essential oils (EOs) $)^{9}$ and antimicrobial peptides. ${ }^{10}$ Our group has nanoformulated antibiotics, ${ }^{11,12}$ antimicrobial biopolymers ${ }^{13}$ and enzymes ${ }^{14}$ for increased antibacterial efficacy, based on bacterial membrane disturbance and rapid bacterial elimination at lower dosage than their bulk counterparts. Targeted delivery of nano-antibacterials to the site of infection is a new approach for potentiating the therapeutic efficacy of antibiotics and reducing their side effects to the beneficial microbiome and human cells. ${ }^{15} \mathrm{Up}$ to date, most targeted nanosystems have been envisaged for improving cancer therapies and imaging diagnosis, ${ }^{16,17}$ while studies focused on bacteria targeting are scarcely reported. Previous works aimed to improve the potency of the last resort antibiotics gentamicin, ${ }^{18} \operatorname{ciprofloxacin}^{19}$ and vancomycin ${ }^{15}$ locally, reduce 
the systematic dose needed and minimize their side effect. Despite the promising outcomes, the use of antibiotics itself entails the possibility of resistance development.

In this study, we generated targeted nanocapsules (NCs) loaded with antibacterial oregano essential oil (EO) for effective elimination of Gram-positive Staphylococcus aureus (S. aureus). S. aureus is one of the most common and problematic bacterial pathogens nowadays that affects nearly half a million people annually ${ }^{20}$ and is the leading cause of variety of diseases, from mild skin infections (e.g. pimples, impetigo, boils, cellulitis, folliculitis) to life-threatening blood stream infections (e.g. pneumonia, meningitis, osteomyelitis, endocarditis and toxic shock syndrome). ${ }^{21}$ The bacterium is included in the list of high priority pathogens threating the human health and has acquired resistance practically to all antibiotics developed since $1940 \mathrm{~s}^{22}$

Plant EOs such as clove, cinnamon, oregano and thyme oils are among the most prospective antibacterial alternatives with demonstrated potential for treatment of $S$. aureus infections and low possibility of inducing resistant appearance. ${ }^{23,24}$ Nevertheless, their direct use or incorporation into disinfectant or drug formulations is precluded by low solubility, chemical instability, high reactivity and potential toxicity/immunogenicity to human cells. ${ }^{25}$ Generating targeted EOcontaining NCs is expected to overcome these obstacles and further improve the bactericidal potency of the oils coupled to minor side effects on human cells. Herein, self-assembling proprietary nanoencapsulation technology ${ }^{26}$ based on the biocompatible and biodegradable plant protein zein, was employed for the production of highly antibacterial oregano EO-loaded zein NCs (here referred as EO NCs). The nano-formulation of the EO is envisaged to enhance its antibacterial activity when compared to the pristine solution. Coating of the EO NCs with aminocellulose $(\mathrm{AC})$ is aimed at providing reactive groups on the NCs surface for grafting of a specific for $S$. aureus antibody. The EO NCs functionalization with targeting antibody will 
increase the NCs bactericidal efficacy against the Gram-positive $S$. aureus at lower dosage and at the same time will reduce the toxic effects to non-targeted bacteria and human cells. Quartz crystal microbalance with dissipation monitoring (QCM-D) will be used to assess in real time and under dynamic conditions the interactions of the targeted NCs with $S$. aureus leading to bacterial eradication. The selective antibacterial activity of the antibody functionalized EO NCs towards $S$. aureus will be further evaluated in vitro in a single and mixed bacterial inoculum with non-targeted P. aeruginosa. Finally, the biocompatibility and the treatment efficacy will be validated in an in vitro co-culture model comprising human fibroblast cells and S. aureus bacterium. 


\section{RESULTS AND DISCUSSIONS}

\subsection{Targeted NCs formulation and characterization}

EO NCs were produced using a proprietary self-assembling nanoencapsulation technology ${ }^{26}$ based on propylene glycol, a water miscible non-volatile organic solvent, and zein, a hydrophobic protein found in maize. The technology is simple, versatile and allowed the formation of stable and homogenous zein NCs loaded with the hydrophobic oregano EO from Thymbra capitata. ${ }^{26}$ High EO encapsulation efficiency (EE), of about $86 \%$, was determined by carvacrol quantification with high performance liquid chromatography (HPLC). Zein NCs containing EO with size of $94 \pm 3.7$ $\mathrm{nm}$, low polydispersity index $(<0.2)$ and $-33 \pm 0.5 \mathrm{mV} \zeta$-potential (at pH 3.3) (Figure 1B), indicating uniform size distribution and colloidal stability, were stored for 6 months at room temperature without any visible signs of aggregation and precipitation. The negative surface charge of the EO NCs could be due to the surfactant excipients employed to provide higher colloidal stability of the final formulation or modulation of the zein conformation upon nanotransformation. ${ }^{27-29}$ As anticipated, and based on our previous experience, ${ }^{13,30}$ the EO encapsulation led to enhanced antibacterial efficacy against the targeted $S$. aureus at lower dosage, when compared to the same amount of the pristine oil (Supporting Information, Figure S1).

The negatively charged EO NCs were further coated with positively charged AC $(36.4 \pm 0.75 \mathrm{mV})$, following the principles of electrostatic driven self-assembling, to introduce more reactive amino groups on the NCs surface for grafting of the $S$. aureus targeting antibody (Figure 1A). AC is derivative of cellulose with improved cationic character, which is obtained by applying chemoand regioselective nucleophilic displacement reaction of p-toluenesulfonic acid ester of cellulose with ethylendiamine. ${ }^{13}$ The AC deposition onto the EO NCs led to a change of the $\zeta$-potential from 
$-33 \pm 0.5$ to $+33.8 \pm 0.4 \mathrm{mV}$ (Figure $1 \mathrm{~B}$ ), as well as an increase of the size from $94 \pm 3.7 \mathrm{~nm}$ to $114 \pm 3.5 \mathrm{~nm}$. The presence of amino groups on the AC decorated EO NCs (AC_EO NCs) surface was confirmed by staining with fluorescamine reagent. The amount of available primary amino groups on the NCs was 27-fold higher in the case of the AC_EO NCs than the pristine EO NCs, where negligible amounts $\left(1.4 \mu \mathrm{g} \mathrm{mL}^{-1} \pm 0.2\right)$, originating from the low available lysine and arginine zein amino acids, ${ }^{31}$ were determined. These AC_EO NCs demonstrated enhanced antibacterial efficacy against $S$. aureus than the pristine EO NCs at the same concentrations $\left(\approx 1.5 \times 10^{9} \mathrm{NCs} \mathrm{mL}^{-1}\right)$, due to the higher availability of primary amino groups, leading to improved interaction and disruption of bacterial membrane (data not shown). ${ }^{13,30}$ Consequently, those groups were lost upon the immobilization of the targeting antibody. This was confirmed by the changes in the zeta potential from positive to negative for the $\mathrm{Ab} @ \mathrm{NCs}$ (Figure 1B), suggesting that the AC would not play a role in the NCs antibacterial function.

The AC_EO NCs were functionalized with a specific against $S$. aureus ${ }^{18}$ antibody by carboxyl-toamine crosslinking using 1-ethyl-3-(3-dimethylaminopropyl) carbodiimide and Nhydroxysulfosuccinimide to obtain the targeted $\mathrm{Ab} @ \mathrm{EO} \mathrm{NCs}$ (Figure 1A). Prior to immobilization, the specificity of the antibody towards the targeted bacterium was confirmed using a secondary antibody conjugated to the enzyme horseradish peroxidase ${ }^{32}$ The development of green color was observed only in those samples where S. aureus bacterium was present, but was not detected in the control sample of the non-targeted P. aeruginosa, indicating the specific interaction with the bacterium of our interest (Figure 1C).

Considering the fact that the carboxyl groups are ubiquitous throughout the antibody's structure including the antigen binding site, the binding affinity of the immobilized onto the EO NCs antibody with the antigen was assessed using fluorescein isothiocyanate (FITC)-conjugated 
protein A from S. aureus (Figure 1D). ${ }^{33}$ The FITC-protein A binding with the Ab@EO NCs resulted in a green fluorescent light emission measured at $525 \mathrm{~nm}$ using fluorescence spectrophotometer (Supporting Information, Figure S3). The green light from the Ab@EO NCs was also observed by a fluorescence microscope (Figure 1E). Such behavior was not found in the EO NCs, which evidenced the successful grafting of the antibody able to interact with the protein A at $S$. aureus surface.

The developed Ab@EO NCs had a mean size of about $134.9 \pm 13.2 \mathrm{~nm}$ and $-28.63 \pm 1.19 \mathrm{mV} \zeta-$ potential (Figure 1B). This high $\zeta$-potential $(\geq 20 \mathrm{mv})$ was further reflected in high colloidal stability, without any visible signs of precipitation, for a long period (up to 6 months) of storage at $4{ }^{\circ} \mathrm{C}$. The $\mathrm{Ab} @ \mathrm{EO}$ NCs size distribution profile, obtained by nanoparticle tracking analysis (NTA), showed predominantly three size subtypes at $96.4 \pm 9.8 \mathrm{~nm}, 133 \pm 8.6$ and $180.9 \pm 23.7$ $\mathrm{nm}$, with considerably narrow distribution profile and low polydispersity (Supporting Information, Figure S2). Furthermore, the morphology and the size of the Ab@EO NCs were examined by transmission electron microscopy (TEM). The images revealed predominantly sphere-like shaped $\mathrm{Ab} @ \mathrm{EO} \mathrm{NCs}$ with size distribution in the range between 60 to $140 \mathrm{~nm}$ (Figure 1F and G), similar to the results obtained by NTA (Supporting Information, Figure S2). Small aggregates due to the samples drying during the preparation for TEM analysis could be also observed. 

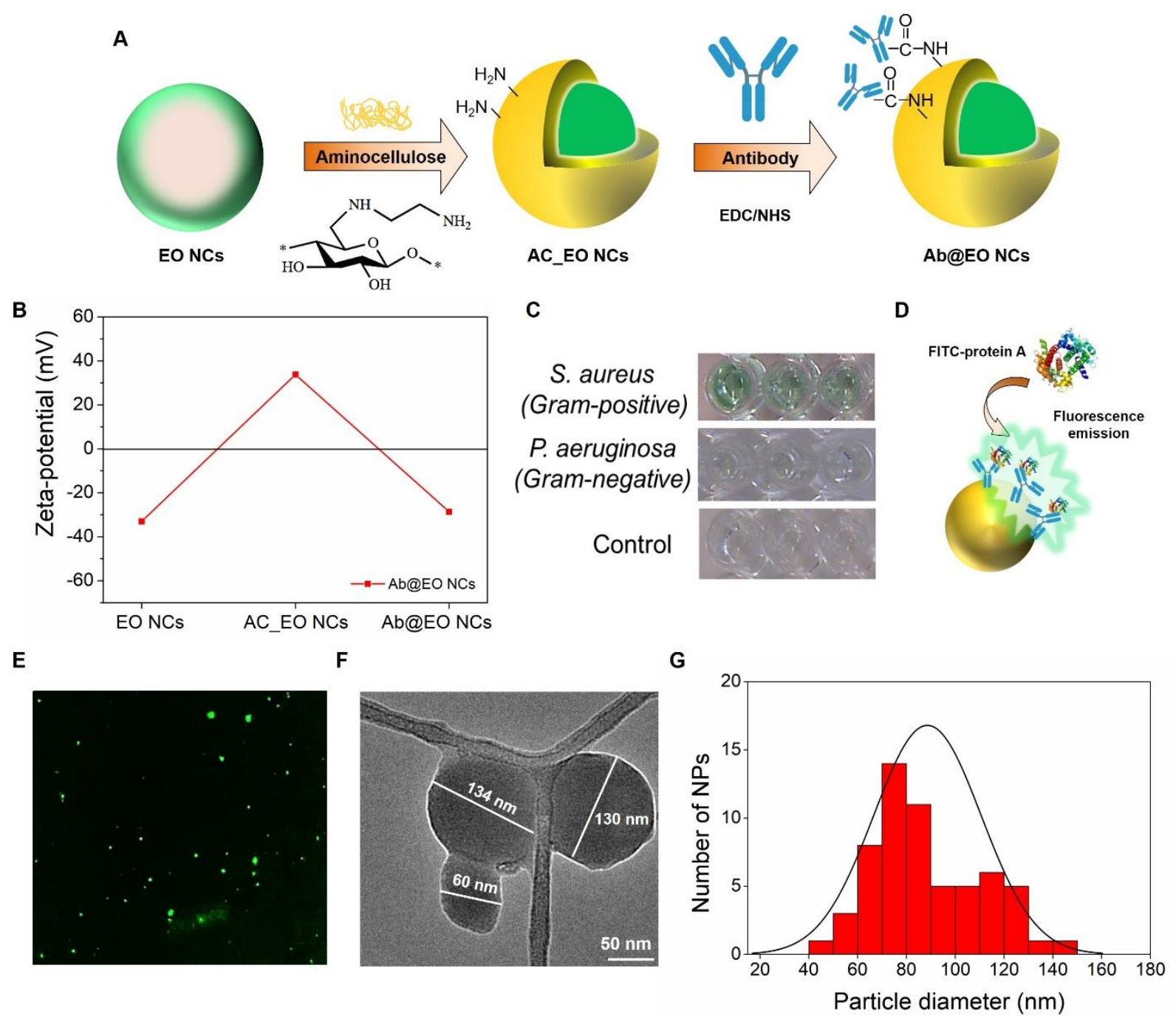

Figure 1 Fabrication and characterization of Ab@EO NCs. A) Schematic representation of Ab@EO NCs preparation. B) ל-potential values for pristine EO NCs, AC_EO NCs and Ab@EO NCs dispersed in MilliQ water. C) Green color development after antibody interaction with targeted S. aureus. D) Interaction of antibody-enabled EO NCs with FITC-labelled protein A and E) Florescence microscopy images of FITC-protein A bound Ab@EO NCs. F) TEM images of Ab@EO NCs at different magnifications. G) Histogram of the Ab@EO NCs size distribution based on the total count of 60 NPs using ImageJ software. 


\subsection{Antibacterial activity towards $S$. aureus}

The antibacterial efficiency of the developed non-targeted and targeted EO NCs was assessed in vitro against $S$. aureus by quantitative plate count method. EO NCs effectively reduced the growth of $S$. aureus at 4-fold lower concentrations than the bulk oil (Figure 2 and Supporting Information, Figure S1). The active principle of the NCs - oregano EO is composed of oxygenated monoterpenes $(77.5 \%$ of the composition), being the monoterpenoid carvacrol the main antibacterial constituent $(73.8 \%) .{ }^{34}$ This monoterpenoid is the component responsible for the strong antimicrobial activity of the oregano oil against both Gram-negative and Gram-positive bacteria, and its higher bactericidal effect at very low concentrations than other known EO such as clove bud and thyme. ${ }^{35}$ It has been proved that carvacrol can affect the lipids' ordering and stability of bacterial membrane that in turn increases the membrane permeability, causing cellular lysis and death. Additionally, carvacrol may inactivate intracellular components, such as enzymes involved in energy production, which also lead to bacterial damaging and elimination. ${ }^{36,37}$

Although the non-targeted EO NCs were active against $S$. aureus, they showed lower antibacterial activity than the developed $\mathrm{Ab} @ \mathrm{EO} \mathrm{NCs}$ at the same concentrations $\left(1.5 \times 10^{9} \mathrm{NCs} \mathrm{mL}^{-1}\right)$. Up to 2-fold improvement was observed for Ab@EO NCs because the antibody drives the bactericidal EO NCs directly to the $S$. aureus, increasing the local bactericide concentration on the bacterial surface for a short period of time and thus potentiating its bactericidal efficacy (Figure 2). 


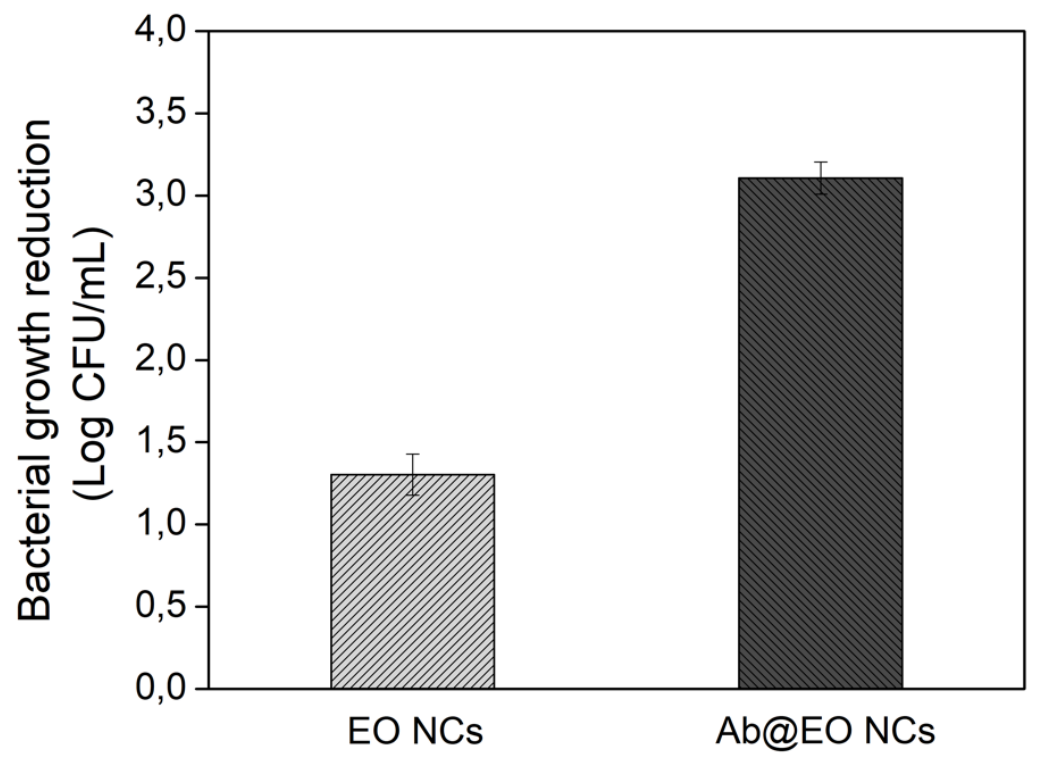

Figure 2 Antibacterial activity of EO and $\mathrm{Ab} @ \mathrm{EO} \mathrm{NCs}$ (concentration $\approx 1.5 \times 10^{9} \mathrm{NCs} / \mathrm{mL}$ ) against S. aureus.

\subsection{Real-time monitoring of the NCs interaction with S. aureus}

QCM-D was used to monitor in real time the effect of the $\mathrm{Ab} @ \mathrm{EO}$ NCs on the targeted bacterium under dynamic conditions. QCM-D allows to study the NCs-cells interactions as the piezoelectric mass sensing together with the monitoring of dissipation changes provide information about the different stages of bacterial growth, e.g. cells attachment, biofilm formation, cellular lysis and dispersion. ${ }^{38}$ This technique has been routinely used in our group to study the toxic effects of antibacterial nanomaterials on biomimetic bacterial and mammalian membranes, as well as to identify time-dependent changes in bacterial attachment and growth. ${ }^{14}$ In this work, S. aureus was first deposited onto the QCM sensor and the changes in the frequency and dissipation upon the circulation of the targeted and non-targeted EO NCs were assessed (Figure 3). At first, the addition 
of the bacterial inoculum caused a rapid decrease of the frequency $(\approx 20 \mathrm{~Hz})$ (Figure 3, zone II) from the $100 \mathrm{mM}$ phosphate buffered saline (PBS) baseline (Figure 3, zone I), attributed to the combined effect of fast "bulk shift" caused by the change from PBS to Mueller Hinton broth (MHB), and the adsorption of MHB components and bacterial cells onto the disk. ${ }^{14}$ After $3 \mathrm{~h}$ of circulation, adhesion of $S$. aureus was achieved, as confirmed by the decrease of the frequency and increase in the dissipation (Figure 3, zone II). This was supported by the results obtained following a PBS rinse of loosely adhered cells (Figure 3, zone III), leading to a slight frequency increase/dissipation decrease and ultimately the establishment of a steady-state frequency and dissipation signals at levels lower than the original baseline (Figure 3, zone I).

Following the formation of stable S. aureus adlayer, the NCs were flowed-through with a speed of $20 \mu \mathrm{L} \mathrm{min}{ }^{-1}$ at $37{ }^{\circ} \mathrm{C}$ for $45 \mathrm{~min}$. The injection of the $\mathrm{Ab} @ \mathrm{EO}$ NCs caused a decrease of the frequency, possibly translated into a rapid removal of the cells from the sensor (Figure 3, zone IV). Upon PBS rinsing the frequency decrease remained stable at the level of the clean, i.e. bacteriafree crystal (Figure 3, zone I), implying a decrease of the cellular mass and almost complete $S$. aureus elimination from the surface. ${ }^{38,39}$ Moreover, the Ab@EO NCs led to change in the dissipation shifts, which was ascribed to increased water content, rearrangements of the cells on the crystal surface, and morphology changes. ${ }^{14}$ Similar tendency was obtained for the control EO NCs, however, the frequency measurements reached a stable state at higher levels $(\cong-15 \mathrm{~Hz})$ than the Ab@EO NCs $(\cong-5 \mathrm{~Hz})$, suggesting a lower efficacy of these NCs against the targeted cells (Figure 3, zone V). These results corroborated the improved killing efficacy of the Ab@EO NCs compared to the pristine EO NCs observed in the antimicrobial tests (Figure 2). Such behavior was not observed when the experiments were performed with the non-targeted $P$. aeruginosa cells (Supporting Information, Figure S4). Therefore, targeting via antibody specific against $S$. aureus 
could be a way to ensure the rapid delivery of the nanoformulated bactericide and the effective elimination of the pathogen from the site of infection.

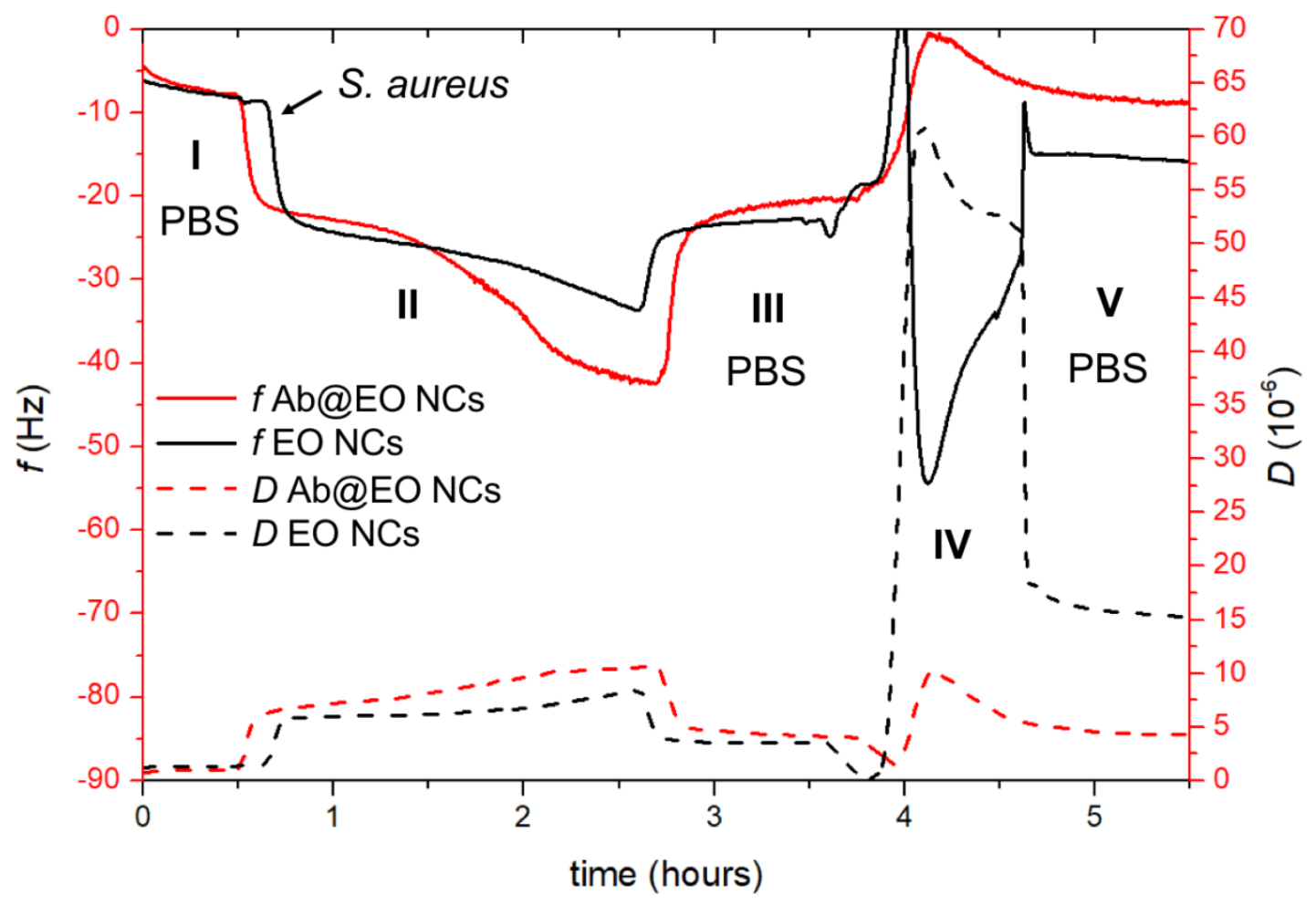

Figure 3 Interaction of EO NCs and Ab@EO NCs with S. aureus assessed by QCM-D. The shift in the frequency and dissipation are represented with solid and dashed lines, respectively. The numbers I, II, III, IV and V indicate the different zones, respectively the baseline with PBS, bacterial adhesion, baseline after washing of loosely adherent cells, NCs insertion and PBS washing.

\subsection{Selective antibacterial activity of the Ab@EO NCs towards targeted $S$. aureus}

S. aureus is an opportunistic human pathogen, found in many skin infections ${ }^{40}$ Currently, skin infections control has been made with antiseptics (e.g. chlorhexidine and triclosan) and antibiotics (e.g. mupirocin and fusidic acid), which also affect the beneficial skin microbiota, increase the risk 
of AMR appearance and at higher amounts may cause side effects. ${ }^{41}$ In this work, we aimed to developed targeted bactericidal nanosystems to selectively eradicate the $S$. aureus pathogen, without affecting other beneficial bacterial strains. The specific action of the Ab@EO NCs on the targeted $S$. aureus was confirmed in vitro upon their incubation with a mixed inoculum containing S. aureus and non-targeted $P$. aeruginosa as model Gram-negative bacterium found in the skin flora (Figure 4A). The bacterial viability after exposure to the antibody-functionalized and nonfunctionalized EO NCs was assessed by plating on selective for $S$. aureus and P. aeruginosa agars. As expected, the EO NCs demonstrated antibacterial effect on both bacteria (Figure 4B). Up to 1.9 and $1.3 \log$ reduction was obtained for $S$. aureus and P. aeruginosa, respectively. In contrast, the EO NCs tagged with specific for S. aureus antibody, resulted in more localized delivery of the nano-sized bactericide to the target and up to $3 \log$ reduction of the initial bacterial load was obtained. Such effect, however, was not observed for the non-targeted $P$. aeruginosa, due to the absence of the specific ligand that could drive the antibacterial EO NCs to the target (Figure 4B).

The selective bactericidal activity of the Ab@EO NCs was further studied using scanning electron microscopy (SEM). The SEM images demonstrated that the control $S$. aureus and $P$. aeruginosa cells without the NCs were intact and did not present any morphological changes (Figure 4C). $S$. aureus appeared spherical with size of up to $1 \mu \mathrm{m}$ in diameter, while P. aeruginosa were rodshaped measuring 0.2 to $0.4 \mu \mathrm{m}$ in width and 1 to $1.5 \mu \mathrm{m}$ in length. Clear differences between the control and the bacteria treated with EO NCs and Ab@EO NCs were observed. In the case of EO NCs, changes in the surface morphology of both $S$. aureus and P. aeruginosa cells associated with cellular dead could be detected (Figure 4C), which is in agreement with the results from the live cells counting (Figure 4B). On the other hand, the interactions driven by the antibody functionalization do not seem to induce any antibacterial effect on the non-targeted $P$. aeruginosa, 
since the overall microorganism morphology was not affected and appeared similar to the control without bactericidal treatment. This, however, was not found for $S$. aureus and significant morphological changes were observed after incubation with Ab@EO NCs (Figure 4C). The altered cell morphology indicated cell damage, which eventually led to leakage of cytoplasmic contents and cellular death. These results corroborated the selective antibacterial efficacy observed in the quantitative plate count method (Figure 4B), and therefore confirmed that in mixed bacterial inoculum the antibody functionalized NCs specifically interact with the $S$. aureus surface and could be used for effective elimination of this bacterium at the site of infection.

A

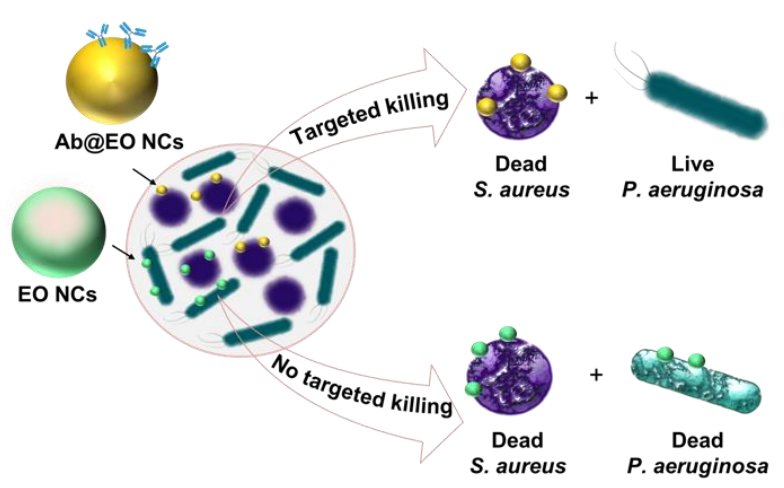

B

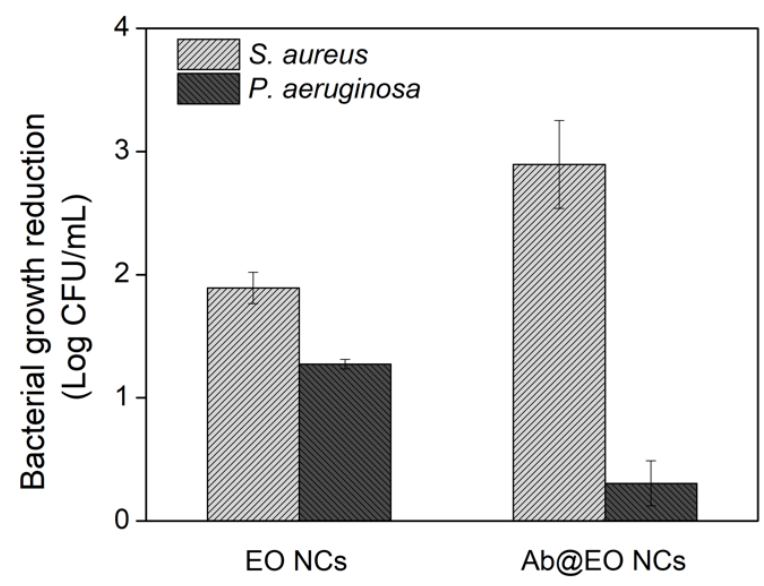



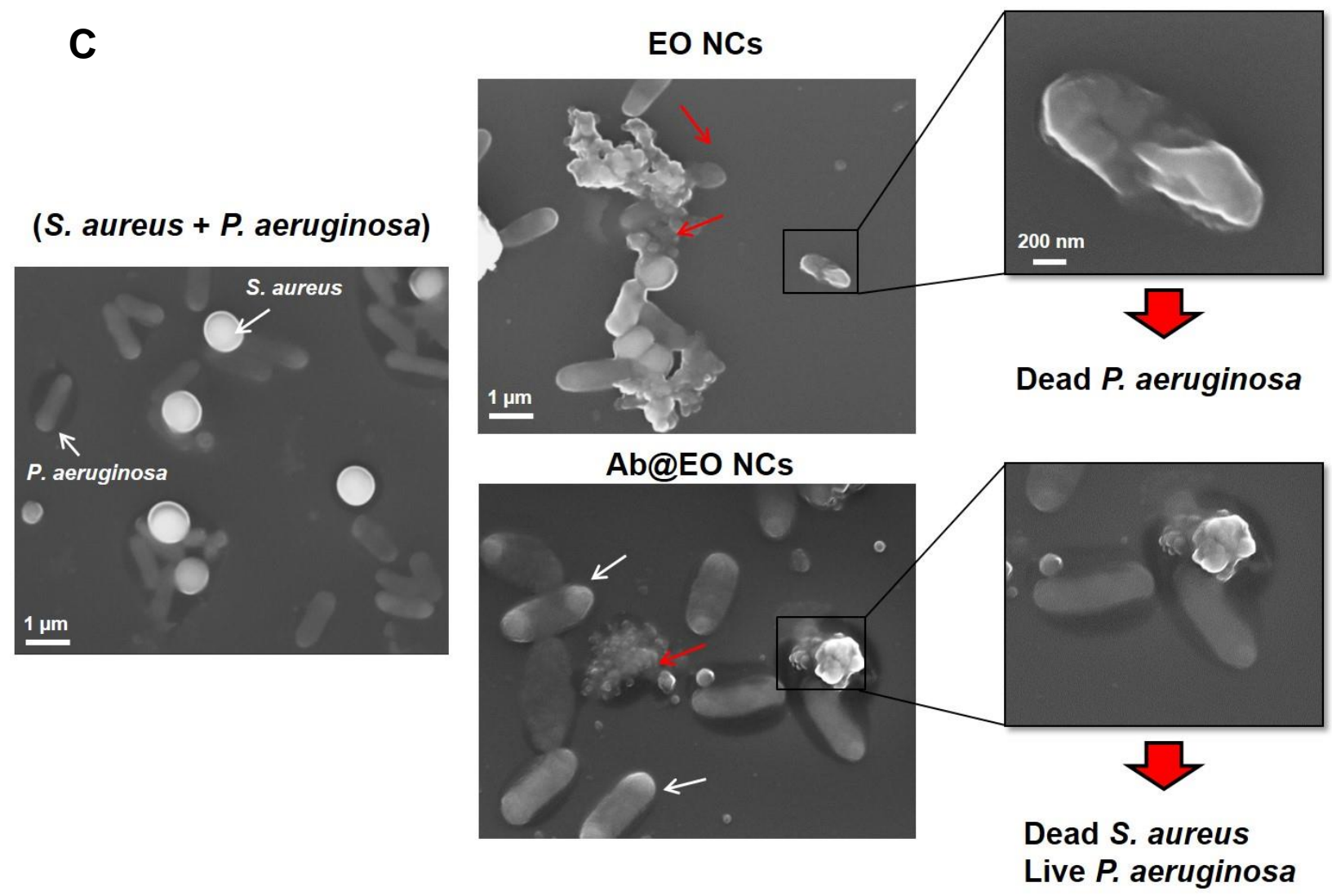

Figure 4 Antibacterial activity of EO NCs and $\mathrm{Ab} @ \mathrm{EO}$ NCs in mixed bacterial inoculum. A) Schematic representation of the EO NCs and $\mathrm{Ab} @ \mathrm{EO}$ NCs interaction with $\mathrm{S}$. aureus and $P$. aeruginosa, when are growing together. B) S. aureus and P. aeruginosa growth reduction (Log $\left(\mathrm{CFU} \mathrm{mL} \mathrm{m}^{-1}\right)$ ) upon exposure to the EO NCs and Ab@EO NCs. C) SEM images of S. aureus (roundshaped) and P. aeruginosa (rod-shaped) bacteria without any treatment and incubated with EO NCs and Ab@EO NCs. White and red arrows indicate live and damaged bacterial cells, respectively.

\subsection{Cytotoxicity of the Ab@EO NCs}

Nanoformulation of EO represents an effective approach to enhance their physical stability and potentiate the bactericidal activity towards both susceptible and AMR bacteria. ${ }^{42}$ However, the potential toxicity of the nano-sized materials, associated with their unique physico-chemical 
properties may impede their biomedical application. The cytotoxicity of the developed Ab@EO NCs was evaluated in vitro on human fibroblasts cells using AlamarBlue ${ }^{\circledR}$ reagent for quantification of the metabolically active cells, and Live/dead ${ }^{\circledR}$ viability/cytotoxicity assay kit for microscopic visualization of live and dead cells. The Live/Dead ${ }^{\circledR}$ assay kit is based on the simultaneous determination of live and dead cells with two fluorescence probes: i) calcein, which is well retained within the live cells, producing green fluorescence and ii) ethidium homodimer-1 that enters cells with damaged membranes producing red fluorescence in the dead cells.

The results from both tests did not show any significant cytotoxicity and antiproliferative effect of the Ab@EO NCs on the human cells after $24 \mathrm{~h}$ of exposure at their bactericidal effective concentration. Up to $80 \%$ of the skin fibroblasts were metabolically active, as calculated in comparison to the control - cells without NCs, indicating desirable innocuousness of the novel $\mathrm{Ab} @ \mathrm{EO} \mathrm{NCs}$ for therapeutic antibacterial applications (Figure 5A). Additionally, fluorescence microscopic images after live/dead staining demonstrated that the NCs did not induce any changes in the cellular morphology and most of the cells were alive, thus appeared green (Figure 5B). 
A

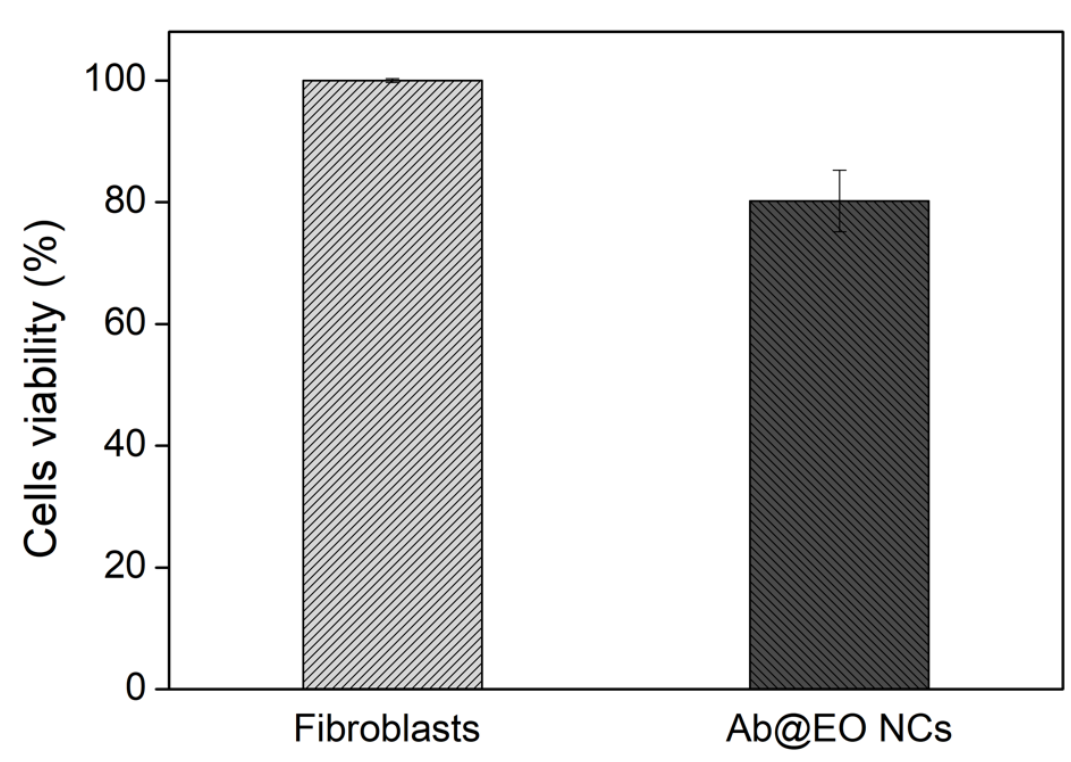

B

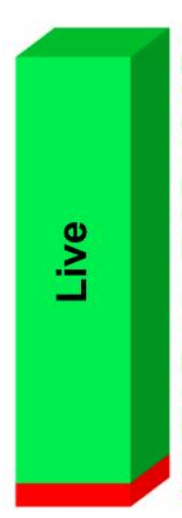

Skin Fibroblasts

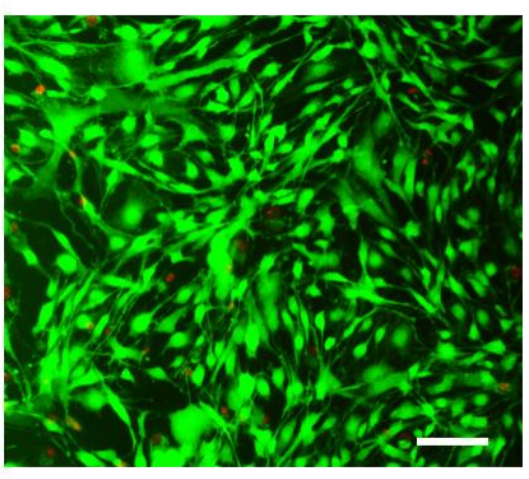

Ab@EO NCs

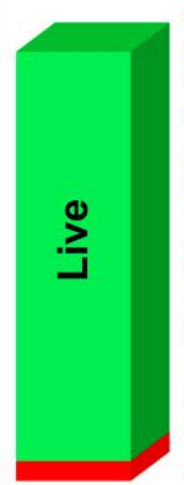

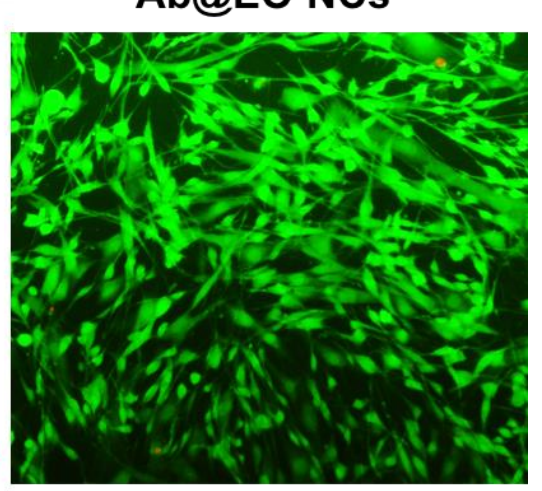

Figure 5 Cytotoxicity of Ab@EO NCs. A) Viability (\%) of human fibroblasts exposed to Ab@EO NCs after $24 \mathrm{~h}$ of incubation, determined by AlamarBlue assay. B) Live/Dead assay of human fibroblasts after 24 h exposure to Ab@EO NCs. Overlapped images of live (green) and dead (red) cells. The bars aside each image represent the green and fluorescence intensities obtained after measuring at $\lambda_{\mathrm{ex} / \mathrm{em}}=494 / 517 \mathrm{~nm}$ and $\lambda_{\mathrm{ex} / \mathrm{em}}=528 / 617 \mathrm{~nm}$ for calcein and ethidium homodimer1 , respectively. Scale bar corresponds to $100 \mu \mathrm{m}$. 


\subsection{Antibacterial efficacy of the Ab@EO NCs in an in vitro co-culture model of $S$. aureus and}

\section{human cells}

Finally, the selective bacterial eradication and treatment efficacy of the Ab@EO NCs was evaluated in an in vitro co-culture model composed of the target $S$. aureus bacterium and human skin fibroblasts, which are critical for the skin healing and recovery. ${ }^{43}$ Human cells were infected with $S$. aureus and then exposed to the $\mathrm{Ab} @ \mathrm{EO} \mathrm{NCs}$ at their defined antibacterial dosage. Afterwards, $S$. aureus bacterial growth was quantified via a plate count method, while the viability of the skin fibroblasts was determined by Live/dead ${ }^{\circledR}$ viability/cytotoxicity assay kit. The fluorescence microscopy images after staining of the co-cultured cells demonstrated the negative (i.e. lethal) effect of $S$. aureus on the human cells, supported by the increased number of dead fibroblasts. S. aureus produces a variety of toxins (e.g. hemolysins and leukotoxin) to damage biological membranes and cause cells death during the infection establishment. The bacterium has been reported to induce direct cytotoxic effect on different human cells, organs, and tissues. ${ }^{40}$ In contrary to the non-treated sample, single supplementation of the targeted NCs protected the fibroblast cells from the $S$. aureus-induced cellular damaging, preserving the cells viability and morphology (Figure 6). At the same time the S. aureus growth was inhibited by $80 \%$ (Supporting Information, Figure S5). It is worth mentioning that despite the promising antibacterial activity of pristine EO NCs (Figure 2 and 3), these demonstrated negligible bactericidal effect on S. aureus in our in vitro infection model in comparison to the $\mathrm{Ab} @ \mathrm{EO} \mathrm{NCs}$, and at the same time did not maintain the skin fibroblasts viability (Supporting Information, Figure S6). Therefore, the developed in this work novel Ab@EO NCs are effective and safe antibacterial agents for selective elimination of the pathogen. Antibody-enabled targeting of the antibacterial EO is a promising 
strategy to boost their bactericidal activity towards $S$. aureus and lower the adverse effects on the human cells.
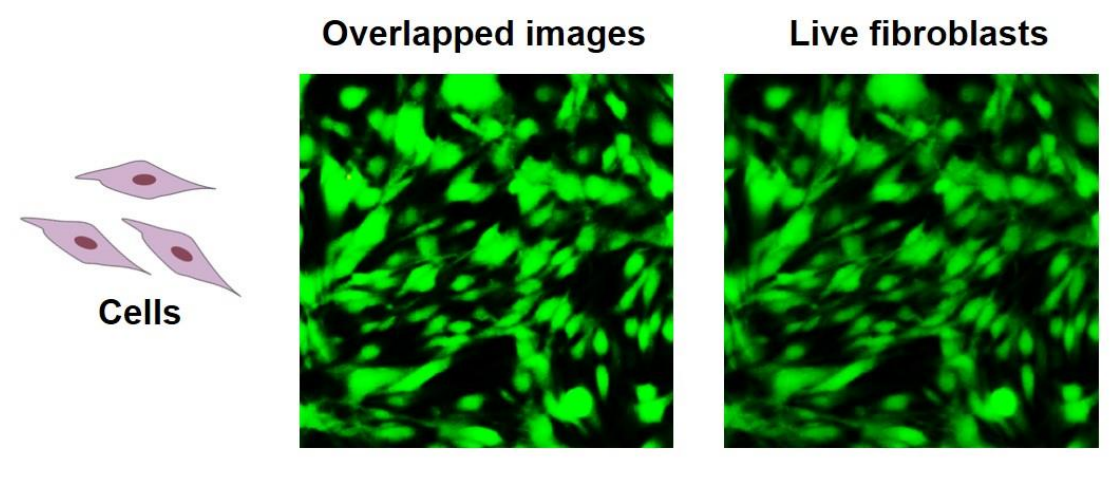

\section{Dead fibroblasts}
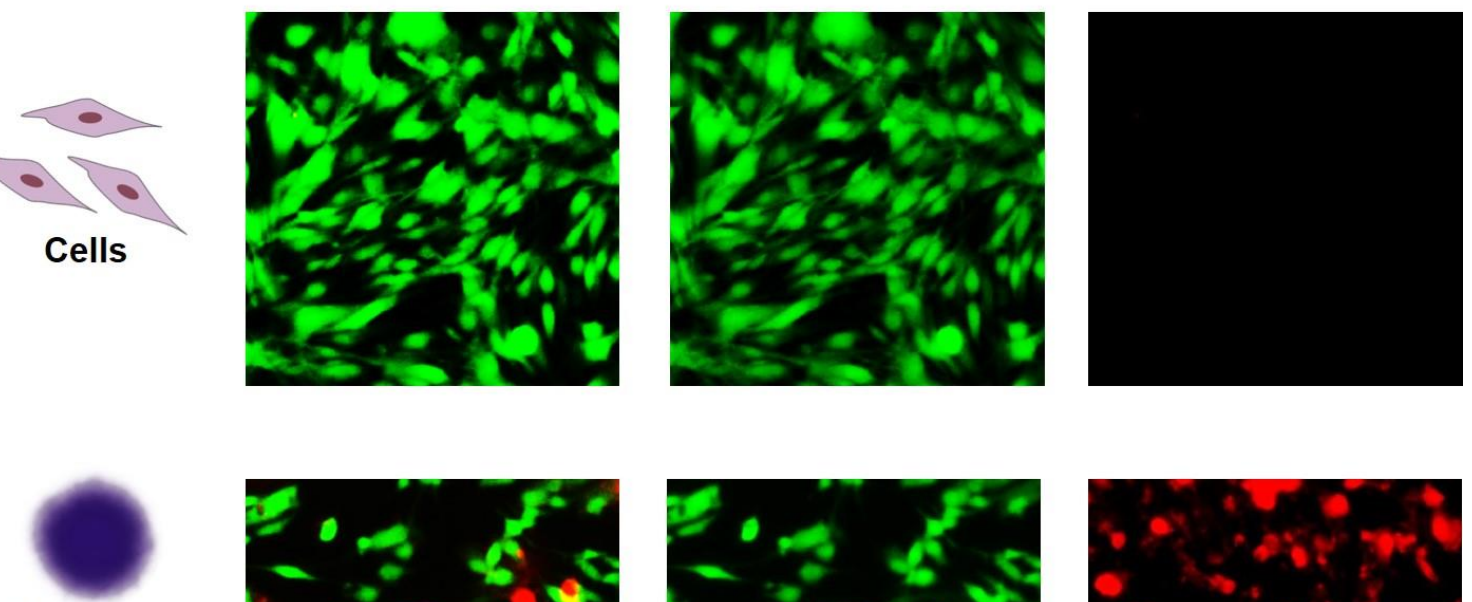

S. aureus
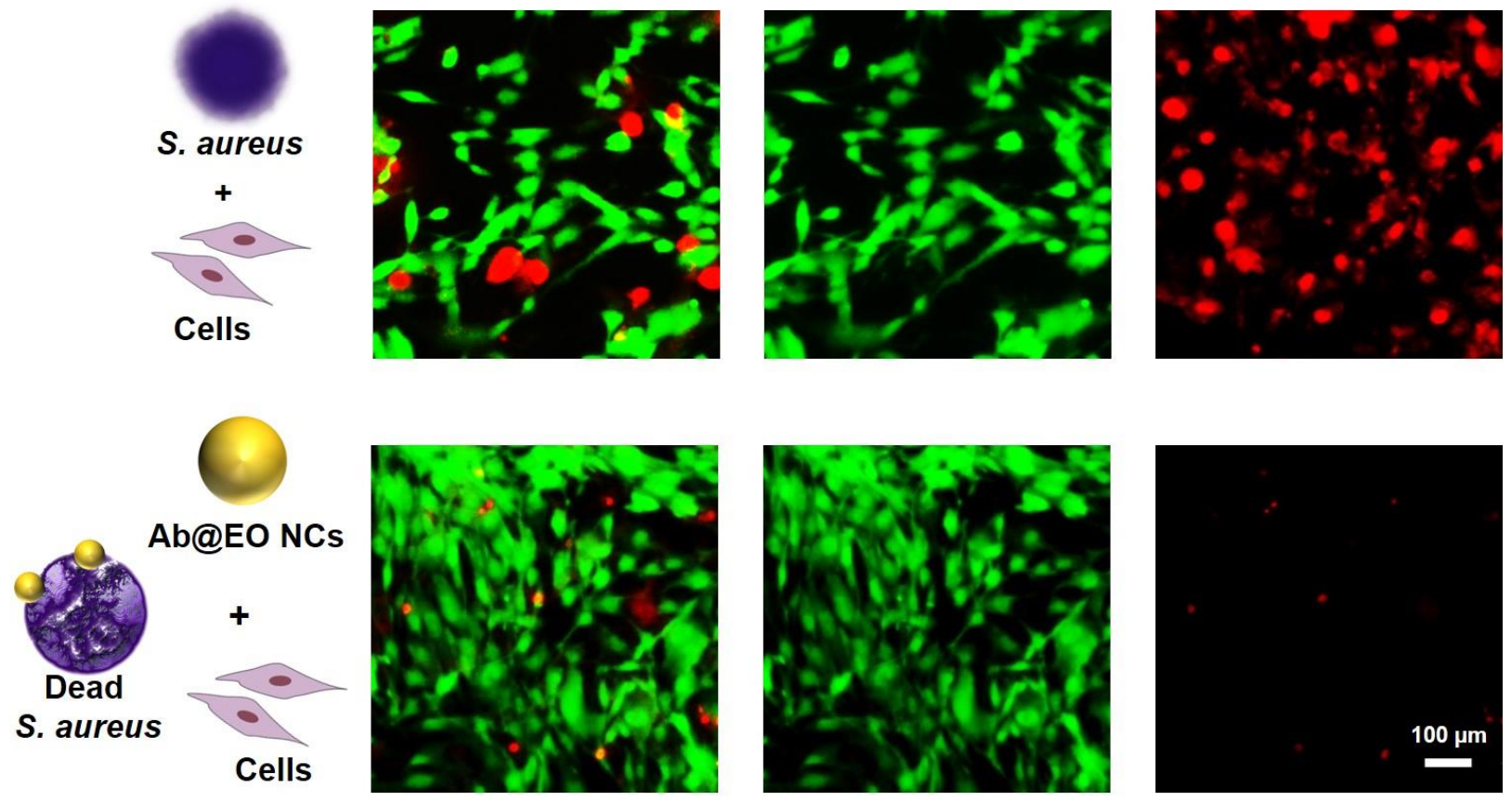

Figure 6. Live/Dead kit staining of non-infected and $S$. aureus infected human cells with and without treatment with $\mathrm{Ab} @ \mathrm{EO}$ NCs. 


\section{CONCLUSIONS}

AMR has raised the need for engineering novel highly effective antibacterials with reduced toxicity and lower selection for resistant bacterial strains. Herein, a novel targeted antibacterial strategy for selective elimination of Gram-positive S. aureus was developed based on plant derived bactericidal EO with low potential for resistance development. At first, stable and highly antibacterial EO NCs were formulated by self-assembling nanoencapsulation technology employing the plant-derived protein zein. The EO NCs with improved efficacy compared to the bulk oil bactericidal effect, were further coated with the biocompatible and biodegradable AC to introduce more reactive groups onto the NCs surface for chemical immobilization of the S. aureus targeting antibody. The antibody-enabled EO NCs, combined the high reactivity of the nanoform with specific driving force of the antibody, generating novel nanosystem with enhanced antibacterial activity and potential to selectively eradicate $S$. aureus, preserving the non-targeted P. aeruginosa bacterium alive. Moreover, the Ab@EO NCs inhibited the S. aureus growth and protected the skin fibroblast cells from this pathogen, as was confirmed in an in vitro infection model. These results demonstrated the capacity of the Ab@EO NCs to reach and attack only the pathogen of interest, and thus could be an efficient therapeutic approach for managing S. aureus infections, avoiding the use of antibiotics and preventing from the appearance of AMR. 


\section{MATERIALS AND METHODS}

\subsection{Materials}

Zein, a protein extracted from maize was obtained from Flo Chemical Corporation (MA, USA) and used for the NCs preparation. Oregano EO from Thymbra capitata (100\% pure) was kindly provided by the TELIC S.A. (Barcelona, Spain). 6-deoxy-6-( $\omega$-aminoethyl) AC was purchased from Centre of Excellence of Polysaccharide Research (Germany). MHB, obtained from SigmaAldrich (Spain), was used as growth medium in all antibacterial tests. Baird-Parker and Cetrimide selective agars for culturing and enumeration of $S$. aureus and $P$. aeruginosa, respectively, were also purchased from Sigma-Aldrich (Spain). The bacterial strains S. aureus (ATCC 25923), P. aeruginosa (ATCC 10145), and the human foreskin fibroblast cells (ATCC CRL-4001, BJ-5ta) were obtained from American Type Culture Collection (ATCC LGC Standards, Spain). AlamarBlue ${ }^{\circledR}$ cell viability reagent and Live/Dead BacLight kit (Molecular probes L7012) were purchased from Invitrogen, Life Technologies Corporation (Spain). Live/Dead ${ }^{\circledR}$ viability/cytotoxicity assay kit for mammalian cells was obtained from Thermo Fischer Scientific (Spain). Ultrapure water (Milli-Q ${ }^{\circledR}$ plus system, Millipore) with $18.2 \mathrm{M} \Omega . \mathrm{cm}$ resistivity was used in all experiments. All other reagents were purchased from Sigma-Aldrich, if not specified otherwise.

\subsection{Protein A antibody interaction with $S$. aureus}

The specificity of the antibody was assessed against the targeted S. aureus bacterium and nontargeted $P$. aeruginosa (as control). Briefly, bacteria were allowed to grow and adhere on the surface of a 96-well polystyrene plate overnight at $37^{\circ} \mathrm{C}$. After washing with PBS, bacteria were incubated for $4 \mathrm{~h}$ at RT with the $100 \mu \mathrm{L}$ of $1 / 500$ diluted in PBS specific antibody against protein 
A of $S$. aureus cell wall. Then, bacteria were incubated for $1 \mathrm{~h}$ at RT with a secondary antibody conjugated to the enzyme horseradish peroxidase. Bacteria binding protein A - antibody were further visualized in green upon the addition of a substrate mixture containing $6.5 \mathrm{mM} \mathrm{4-}$ hydroxybenzoic acid, $1.8 \mathrm{mM}$ 2,2'-azino-bis(3-ethylbenzothiazoline-6-sulfonic acid and 5.1 mM hydrogen peroxide in PBS.

\subsection{Antibody-enabled nanocapsules formulation}

For the EO NCs preparation, zein was dissolved in propylene glycol under magnetic agitation. Then, surfactant (tween 20; Panreac, Madrid, Spain) and co-surfactants (propanediol; Dupont Tate \& Lyle Bioproducts, TN, USA, denatured alcohol; Valencia, Spain and oleic acid; Panreac, Madrid, Spain), where added under agitation until a clear, transparent solution was obtained. Oregano EO was then added to that mixture in order to achieve a homogenous organic phase. The resultant surfactant-EO-zein mixture was added under continuous agitation into water at a ratio 3:7 (organic phase:water) to form EO NCs. Afterwards, $22.5 \mathrm{~mL}$ of the EO NCs (negatively

charged) were mixed with $5 \mathrm{~mL}$ of $10 \mathrm{mg} \mathrm{mL}^{-1} \mathrm{AC}$ aqueous solution, at $\mathrm{pH} 3.3$ and incubated for $1 \mathrm{~h}$ at RT. After that, the sample was centrifuged at $29500 \mathrm{~g}$ for $50 \mathrm{~min}$, resuspended in $3.75 \mathrm{~mL}$ of MilliQ water and sonicated to disaggregate the NCs for 20 min at $20{ }^{\circ} \mathrm{C}$. The NCs were functionalized with rabbit protein A antibody using $50 \mathrm{mM} / 20 \mathrm{mM}$ of EDAC/sulfo-NHS in 100 $\mathrm{mM}$ phosphate buffer, $\mathrm{pH}$ 6.5. The reaction was performed at RT for $24 \mathrm{~h}$ with shaking. Then, the NCs were centrifuged for $40 \mathrm{~min}$ at $18000 \mathrm{rpm}$, resuspended in $500 \mu \mathrm{L}$ of MilliQ water and subjected to further analysis. 


\subsection{Nanocapsules characterization}

The EE was determined by carvacrol quantification via HPLC as described before. ${ }^{44}$ The $\zeta$ potential of the NCs was determined using a Zetasizer Nano ZS (Malvern Instruments Inc., UK). The NCs average size, size distribution and the number of NCs per milliliter were assessed by NTA using the NanoSight NS 300 (Malvern Instruments Inc., UK) in flow mode and software NTA 3.2 to capture several frames of the NCs suspension, obtaining the final concentration and the hydrodynamic diameter of the NCs. This technique is rapid, simple, and reliable method used for nanomaterials characterization that allows the precise measurement of the size distribution.

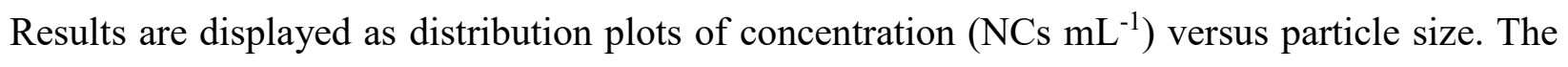
reported average NCs size represents the mean values \pm standard deviations of five measurements per sample. The size and the morphology of the NCs were examined by TEM (Tecnai G2 F20, FEI company, USA) at $80 \mathrm{kV}$ acceleration voltage. Prior observation, $10 \mu \mathrm{L}$ of the samples were placed on ultrathin carbon film on holey carbon grids and air-dried.

The immobilization of active antibody onto the EO NCs was assessed with FITC labelled-protein A. Briefly, $200 \mu \mathrm{L}$ of Ab@EO NCs and EO NCs $\left(3 \times 10^{9} \mathrm{NCs} \mathrm{mL}^{-1}\right)$ were incubated with $2 \mu \mathrm{L}$ FITC-protein A on a dark for $1 \mathrm{~h}$ with $160 \mathrm{rpm}$ shaking. The samples were centrifuged at 25000 $\mathrm{g}$ for $45 \mathrm{~min}$ to remove the excess of FITC-protein A and then resuspended in $200 \mu \mathrm{L} 100 \mathrm{mM}$ phosphate buffer, $\mathrm{pH}$ 6.5. $100 \mu \mathrm{L}$ of the NCs suspension were transferred in 96-black well plates and the fluorescence intensity of each test sample was measured at $\lambda_{\text {exc }} / \lambda_{\mathrm{em}}=490 / 525 \mathrm{~nm}$ using TECAN Infinite M 200 (Austria). In addition, $20 \mu \mathrm{L}$ of the samples were spread on a glass slide and NCs were observed under fluorescence microscope (Nikon/Eclipse Ti-S, the Netherlands). 


\subsection{Quartz crystal microbalance with dissipation monitoring}

The effect of EO and Ab@EO NCs on S. aureus was followed in real time with a QCM-D (E4 system, Q-Sense, Sweden) equipped with Teflon tubing. Gold sensors (QSX 301, QSense, Sweden) were sequentially cleaned in acetone, ethanol and isopropanol in an ultrasonic bath for $10 \mathrm{~min}$ at $40^{\circ} \mathrm{C}$. The sensor was then dried with nitrogen and placed in the QCM-D flow chambers at $37^{\circ} \mathrm{C}$. The experiments were performed under flow-through conditions using a digital peristaltic pump operating in pushing mode for the solutions that were injected into the sensor crystal chamber. At first, a stable baseline with sterile $100 \mathrm{mM}$ PBS, pH 7.4 was acquired at $20 \mu \mathrm{L} \mathrm{min}^{-1}$ at $37^{\circ} \mathrm{C}$. The deposition of $S$. aureus and $P$. aeruginosa cells on the sensor was achieved after $3 \mathrm{~h}$ of circulating of $S$. aureus inoculum $\left(\mathrm{OD}_{600}=0.2\right)$ in MHB. Thereafter, PBS was flowed-through for $\approx 1 \mathrm{~h}$ to remove the loosely deposited bacteria and establish a second baseline. Afterward, EO and $\mathrm{Ab} @ \mathrm{EO} \mathrm{NCs}\left(3 \times 10^{9} \mathrm{NCs} \mathrm{mL}^{-1}\right)$ were circulated for $30 \mathrm{~min}$ at $20 \mu \mathrm{L} \mathrm{min}^{-1}$ and $100 \mathrm{mM} \mathrm{PBS}$, pH 7.4 was flowed to establish the third baseline. The experiments were performed in a triplicate for each sample. To simplify the data interpretation, only the normalized frequency (f) and dissipation (D) shifts as a function of time of one representative sample per experimental group (5th harmonic) are shown.

\subsection{Antibacterial activity tests}

The antibacterial activity of EO NCs and antibody functionalized EO NCs was assessed towards the targeted $S$. aureus in a single and mixed co-culture with non-targeted $P$. aeruginosa. Briefly, bacteria were grown overnight at $37^{\circ} \mathrm{C}$ in $\mathrm{MHB}$ medium. Then, $50 \mu \mathrm{L}$ of the EO NCs and $\mathrm{Ab} @ \mathrm{EO}$

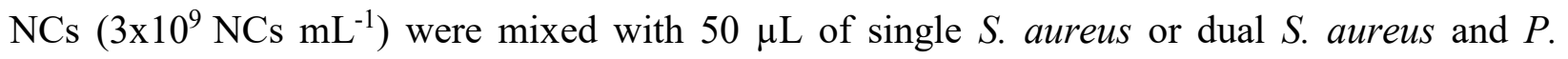
aeruginosa inoculum in $100 \mathrm{mM}$ PBS, $\mathrm{pH} 7.4$ (Final OD $\left.600=0.005, \approx 10^{5}-10^{6} \mathrm{CFU} \mathrm{mL}^{-1}\right)$. The 
samples were incubated for $24 \mathrm{~h}$ at $37^{\circ} \mathrm{C}$ with shaking at $230 \mathrm{rpm}$. The number of survived bacteria during the NCs treatment was determined after plating of $15 \mu \mathrm{L}$ of the suspensions onto specific agar and further incubation for $24 \mathrm{~h}$ at $37^{\circ} \mathrm{C}$. Bacterial inoculum without NCs served as the negative control (no bactericidal activity).

\subsection{Nanocapsules interaction with bacteria assessed by scanning electron microscopy}

The specific interaction of Ab@EO NCs with $S$. aureus in a mixed bacterial inoculum with nontargeted $P$. aeruginosa was studied by SEM. Briefly, $250 \mu \mathrm{L}$ of EO and Ab@EO NCs $\left(3 \times 10^{9} \mathrm{NCs}\right.$ $\mathrm{mL}^{-1}$ ) were mixed with $250 \mu \mathrm{L}$ of bacterial inoculum of S. aureus and P. aeruginosa (Final $\mathrm{OD}_{600}$ $\left.=0.005, \sim 10^{5}-10^{6} \mathrm{CFU} \mathrm{mL} L^{-1}\right)$ in $100 \mathrm{mM}$ phosphate buffer (PB), pH 7.4 for $3 \mathrm{~h}$ at $37^{\circ} \mathrm{C}$ with shaking. After that, bacteria were collected and purified with $100 \mathrm{mM} \mathrm{PB}, \mathrm{pH} 7.4$ by centrifugation (4000 g, $15 \mathrm{~min}$ ). The pellet was resuspended in 2\% paraformaldehyde $/ 2.5 \%$ glutaraldehyde fixative solution (in PB, pH 7.4) and left for overnight at $4{ }^{\circ} \mathrm{C}$. Then, $100 \mu \mathrm{L}$ of the samples were deposited on a glass slide piece. After 30 min, the cells were dehydrated using ascending grades of ethanol ( $25 \%, 50 \%, 75 \%, 100 \%, 1 \mathrm{~h}$ each). After chemical drying with hexamethyldisilazane, the samples were sputter-coated with carbon using Emitech K-950X and analyzed in a Field emissions SEM (JEOL, J-7001F), operating at $10 \mathrm{kV}$ with a secondary electron detector.

\subsection{Biocompatibility evaluation}

Human fibroblast cells were used to determine the toxicity of the NCs as previously described with some modifications. ${ }^{12}$ Briefly, the cells were maintained in Dulbecco's Modified Eagle's Medium (DMEM, ATCC) containing $10 \%(\mathrm{v} / \mathrm{v})$ of fetal bovine serum, $1 \%$ penicillin and $200 \mathrm{mM}$ glutamine, at $37{ }^{\circ} \mathrm{C}$ in a humidified atmosphere with $5 \% \mathrm{CO}_{2}$. At pre-confluence, the cells were harvested using trypsin-EDTA (ATCC-30-2101, $0.25 \%(\mathrm{w} / \mathrm{v})$ trypsin/0.53 mM EDTA solution in 
Hank's BSS without calcium or magnesium) and seeded at a density of $60 \times 10^{4}$ cells per well on a 96-well tissue culture treated polystyrene plate (Nunc). After $24 \mathrm{~h}$, the cells were washed with sterile PBS and the NCs at their bactericidal concentrations were placed in the wells. The cells were incubated at $37^{\circ} \mathrm{C}$ for $24 \mathrm{~h}$. Then, the samples were removed, the growth media withdrawn and the cells were washed with $100 \mathrm{mM}$ PBS, pH 7.4 and stained for $4 \mathrm{~h}$ at $37^{\circ} \mathrm{C}$ with $100 \mu \mathrm{L} 10$ $\%(\mathrm{v} / \mathrm{v})$ AlamarBlue ${ }^{\circledR}$ cell viability reagent in DMEM. Thereafter, the absorbance at $570 \mathrm{~nm}$ was measured, using $600 \mathrm{~nm}$ as a reference wavelength, in a microplate reader. All results are reported as mean values \pm standard deviations $(n=3)$. The cells' morphology and viability were also studied by Live/Dead ${ }^{\circledR}$ viability/cytotoxicity assay kit for mammalian cells. Briefly, the cells were stained for $15 \mathrm{~min}$ in the dark with a mixture of both stains in a ratio calcein: ethidium homodimer (4:1) in PBS. The non-reacted stains were further washed with PBS, and the cells were observed using a fluorescence microscope (Nikon/Eclipse Ti-S, the Netherlands).

\subsection{Antibacterial efficacy of the nanocapsules in an in vitro co-culture model of S. aureus and human cells}

The antibacterial efficacy of the NCs was evaluated in an in vitro co-culture model of human cells and S. aureus. The cells were seeded at a density of $60 \times 10^{4}$ cells per well on a 96-well tissue culture treated polystyrene plate (Nunc) and incubated for $24 \mathrm{~h}$ at $37^{\circ} \mathrm{C}$. Afterwards, the cells were washed with $100 \mathrm{mM}$ PBS, pH 7.4 and inoculated with $100 \mu \mathrm{L}$ of $S$. aureus $\left(\mathrm{OD}_{600}=0.005\right)$ in DMEM (without antibiotic) for $1 \mathrm{~h}$ more to allow bacteria to adhere to the cells. The cells were washed with PBS and then $100 \mu \mathrm{L}$ of the NCs were added at their bactericidal concentrations to test their antibacterial effect on $S$. aureus and the toxicity on the fibroblasts cells. Control samples not treated and not infected, not treated and infected as well as treated with $10 \mu \mathrm{g} / \mathrm{mL}$ gentamycin sulfate were also performed. After $24 \mathrm{~h}$ of incubation, the cells were washed with $100 \mathrm{mM}$ PBS, 
pH 7.4 and $0.5 \%$ Triton X-100 was added for 15 min at $37{ }^{\circ} \mathrm{C}$ to disrupt the cell membrane and obtain the intracellular bacteria. The suspensions were then diluted in $100 \mathrm{mM}$ PBS, pH 7.4 and further seeded on agar plates to count the live bacterial colonies. In a parallel, the cells treated with the NCs were washed and immediately subjected to cytotoxicity assessment using Live/Dead ${ }^{\circledR}$ viability/cytotoxicity kit for mammalian cells as described before.

\section{ASSOCIATED CONTENT}

\section{Supporting Information}

The following files are available free of charge. S. aureus growth reduction after $24 \mathrm{~h}$ incubation with free and encapsulated $\mathrm{EO}$, nanoparticle tracking analysis measurement of $\mathrm{Ab} @ \mathrm{EO} \mathrm{NCs}$, fluorescent intensity measurement upon FITC-protein A incubation with Ab@EO NCs, interaction of EO NCs and Ab@EO NCs with P. aeruginosa assessed by QCM-D, S. aureus growth reduction in an in vitro co-culturing model with human cells, Live/Dead kit staining of S. aureus infected human cells treated with EO NCs.

\section{AUTHOR INFORMATION}

\section{Corresponding Author}

*Tzanko Tzanov, tel.: +34 9373985 70, fax: +34 9373982 25, e-mail: tzanko.tzanov@upc.edu

\section{Author Contributions}

The manuscript was written through contributions of all authors. All authors have given approval to the final version of the manuscript.

\section{Notes}

Any additional relevant notes should be placed here. 


\title{
ACKNOWLEDGMENT
}

This work was supported by the European projects SKHINCAPS "SKin Healthcare by Innovative NanoCAPsuleS" (H2020 - 685909) and PROTECT "Pre-commercial lines for the production of surface nanostructured antimicrobial and antibiofilm textiles, medical devices, and water treatment membranes" (H2020- 720851). A.I. acknowledges the Ph.D. grant (2019FI_B2 00077) provided by the Generalitat de Catalunya. The authors would like to thank the European Regional Development Fund (FEDER).

\begin{abstract}
ABBREVIATIONS
Ab@EO NCs, antibody-enabled EO NCs; AMR, Antimicrobial resistance; AC, Aminocellulose; DMEM, Dulbecco's Modified Eagle's Medium; EE, encapsulation efficiency; EO, essential oil; FITC, fluorescein isothiocyanate; HPLC, high performance liquid chromatography; MHB, Mueller Hinton broth; NCs, nanocapsules; NTA, nanoparticle tracking analysis; PBS, phosphate buffered saline; QCM-D, quartz crystal microbalance with dissipation monitoring; SEM, scanning electron microscopy; TEM, transmission electron microscopy.
\end{abstract}




\section{REFERENCES}

(1) World Health Organization, Global Antimicrobial Resistance Surveillance System (GLASS) Report: early implementation 2016-2017, Geneva, Switzerland 2017.

(2) Davies, J. Origins and Evolution of Antibiotic Resistance. Microbiologia 1996, 12, 9-16.

(3) Knight, G. M.; Costelloe, C.; Deeny, S. R.; Moore, L. S. P.; Hopkins, S.; Johnson, A. P.; Robotham, J. V.; Holmes, A. H. Quantifying Where Human Acquisition of Antibiotic Resistance Occurs: A Mathematical Modelling Study. BMC Med. 2018, 16, 1-11.

(4) Li, B.; Webster, T. J. Bacteria Antibiotic Resistance: New Challenges and Opportunities for Implant-Associated Orthopaedic Infections. J. Orthop. Res. 2018, 36, 22-32.

(5) O’Neill, J. Tackling Drug-Resistant Infections Globally: Final Report and Recommendations. The Review on Antimicrobial Resistance, 2016, 2016, 1-84.

(6) de Kraker, M. E. A.; Stewardson, A. J.; Harbarth, S. Will 10 Million People Die a Year due to Antimicrobial Resistance by 2050? PLoS Med. 2016, 13, 1-6.

(7) Wang, L.; Hu, C.; Shao, L. The Antimicrobial Activity of Nanoparticles: Present Situation and Prospects for the Future. Int. J. Nanomedicine 2017, 12, 1227-1249.

(8) Pham, T. N.; Loupias, P.; Dassonville-Klimpt, A.; Sonnet, P. Drug Delivery Systems Designed to Overcome Antimicrobial Resistance. Med. Res. Rev. 2019, 39, 2343-2396.

(9) Bilia, A. R.; Guccione, C.; Isacchi, B.; Righeschi, C.; Firenzuoli, F.; Bergonzi, M. C. Essential Oils Loaded in Nanosystems: A Developing Strategy for a Successful Therapeutic Approach. Evid. based Complement Alternat. Med. 2014, 2014, 1-14. 
(10) Martin-Serrano, Á.; Gómez, R.; Ortega, P.; Mata, F. J. D. La. Nanosystems as Vehicles for the Delivery of Antimicrobial Peptides (Amps). Pharmaceutics 2019, 11, 1-24.

(11) Fernandes, M. M.; Ivanova, K.; Francesko, A.; Rivera, D.; Torrent-Burguès, J.; Gedanken, A.; Mendonza, E.; Tzanov T. Escherichia coli and Pseudomonas aeruginosa Eradication by Nano-penicillin G. Nanomedicine Nanotechnology, Biol. Med. 2016, 12, 2061-2069.

(12) Fernandes, M. M.; Ivanova, K.; Hoyo, J.; Pérez-Rafael, S.; Francesko, A.; Tzanov, T. Nanotransformation of Vancomycin Overcomes the Intrinsic Resistance of Gram-negative Bacteria. ACS Appl. Mater. Interfaces 2017, 9, 15022-15030.

(13) Fernandes, M. M.; Francesko, A.; Torrent-Burgués, J.; Carrión-Fité, F. J.; Heinze, T.; Tzanov, T. Sonochemically Processed Cationic Nanocapsules: Efficient Antimicrobials with Membrane Disturbing Capacity. Biomacromolecules 2014, 15, 1365-1374.

(14) Ferreres, G.; Bassegoda, A.; Hoyo, J.; Torrent- Burgués, J.; Tzanov, T. Metal-Enzyme Nanoaggregates Eradicate both Gram-Positive and Gram-Negative Bacteria and Their Biofilms. ACS Appl. Mater. Interfaces 2018, 10, 40434-40442.

(15) Hussain, S.; Joo, J.; Kang, J.; Kim, B.; Braun, G. B.; She, Z. G.; Kim, D.; Mann, A. P.; Mölder, T.; Teesalu, T.; Carnazza, S.; Guglielmino, S.; Sailor, M. J.; Ruoslahti, E. Antibiotic-Loaded Nanoparticles Targeted to the Site of Infection Enhance Antibacterial Efficacy. Nat. Biomed. Eng. 2018, 2, 95-103.

(16) Xiao, Z.; Levy-nissenbaum, E.; Alexis, F.; Lupta, A.; Teply, B. A.; Chan, J. M.; Shi, J.; Digga, E.; Cheng, J.; Langer, R.; Farokhzad, O. C. Engineering of Targeted Nanoparticles for Cancer Therapy Using Internalizing Aptamers Isolated by Cell-Uptake Selection. ACS 
Nano 2012, 6, 696-704.

(17) Gu, W.; Zhang, Q.; Zhang, T.; Li, Y.; Xiang, J.; Peng, R.; Liu, J. Hybrid Polymeric NanoCapsules Loaded with Gold Nanoclusters and Indocyanine Green for Dual-Modal Imaging and Photothermal Therapy. J. Mater. Chem. B 2016, 4, 910-919.

(18) Meeker, D. G.; Jenkins, S. V.; Miller, E. K.; Beenken, K. E.; Loughran, A. J.; Powless, A.; Muldoon, T. J.; Galanzha, E. I.; Zharov, V. P.; Smeltzer, M. S.; Chen, J. Synergistic Photothermal and Antibiotic Killing of Biofilm-Associated Staphylococcus aureus Using Targeted Antibiotic-Loaded Gold Nanoconstructs. ACS Infect. Dis. 2016, 2, 241-250.

(19) Zhang, C. Y.; Gao, J.; Wang, Z. Bioresponsive Nanoparticles Targeted to Infectious Microenvironments for Sepsis Management. Adv. Mater. 2018, 30, 1-10.

(20) Tong, S. Y. C.; Davis, J. S.; Eichenberger, E.; Holland, T. L.; Fowler, V. G. Jr. Staphylococcus aureus Infections: Epidemiology, Pathophysiology, Clinical Manifestations, and Management. Clin. Microbiol. Rev. 2015, 28, 603-661.

(21) Balasubramanian, D.; Harper, L.; Shopsin, B.; Torres, V. J. Staphylococcus aureus Pathogenesis in Diverse Host Environments. Pathog. Dis. 2017, 75, 1-13.

(22) Hiramatsu, K.; Katayama, Y.; Matsuo, M.; Sasaki, T.; Morimoto, Y.; Sekiguchi, A.; Baba, T. Multi-drug-resistant Staphylococcus aureus and Future Chemotherapy. J. Infect. Chemother. 2014, 20, 593-601.

(23) Faleiro, M. L.; Miguel, M. G. Chapter 6 - Use of Essential Oils and Their Components against Multidrug-Resistant Bacteria. In Fighting Multidrug Resistance with Herbal Extracts, Essential Oils and Their Components (eds. M. K. Rai, K. V. Kon), Academic 
Press: San Diego 2013, 65-94.

(24) Becerril, R.; Nerín, C.; Gómez-Lus, R. Evaluation of Bacterial Resistance to Essential Oils and Antibiotics After Exposure to Oregano and Cinnamon Essential Oils. Foodborne Pathog. Dis. 2012, 9, 699-705.

(25) Donsì, F.; Ferrari, G. J. Essential Oil Nanoemulsions as Antimicrobial Agents in Food. Biotechnol. 2016, 233, 106-120.

(26) Salman, H. H. A.; Azcarate, I. G.; Catalan I. E. (Bionanoplus, S.L) WO2013120856, Nanoparticles Comprising a Vegetable Hydrophobic Protein and a Water Miscible NonVolatile Organic Solvent and Uses Thereof, Patentscope 2013, 1-108.

(27) Gagliardi, A.; Paolino, D., Iannone, M.; Palma, E.; Fresta, M.; Cosco, D. Sodium Deoxycholate-Decorated Zein Nanoparticles for a Stable Colloidal Drug Delivery System. Int. J. Nanomedicine 2018, 13, 601-614.

(28) Dai, L.; Sun, C.; Wang, D.; Gao, Y. The Interaction between Zein and Lecithin in EthanolWater Solution and Characterization of Zein - Lecithin Composite Colloidal Nanoparticles. PLoS One 2016, 11, 1-20.

(29) Podaralla, S.; Perumal, O. Influence of Formulation Factors on the Preparation of Zein Nanoparticles. AAPS PharmSciTech 2012, 13, 919-927.

(30) Ivanova, A.; Ivanova, K., Hoyo, J.; Heinze, T.; Sanchez-Gomez, S.; Tzanov, T. Layer-ByLayer Decorated Nanoparticles with Tunable Antibacterial and Antibiofilm Properties against Both Gram-Positive and Gram-Negative Bacteria. ACS Appl. Mater. Interfaces 2018, 10, 3314-3323. 
(31) Padua, G. W.; Guardiola, V. Chapter 1: Microcapsules Produced from Zein. In Microencapsulation and Microspheres for Food Applications, (Ed. L. M. C. Sagis), Elsevier Inc, 2015, 1, 1-20.

(32) de La Escosura-Muniz, A.; Ivanova, K.; Tzanov, T. Electrical Evaluation of Bacterial Virulence Factors Using Nanopores. ACS Appl. Mater. Interfaces 2019, 11, 13140-13146.

(33) Welch, N. G.; Scoble, J. A.; Muir, B. W.; Pigram, P. J. Orientation and Characterization of Immobilized Antibodies for Improved Immunoassays. Biointerphases 2017, 12, 1-13.

(34) Ivanova, A.; Ivanova, K.; Tzanov, T. Inhibition of Quorum-Sensing: A New Paradigm in Controlling Bacterial Virulence and Biofilm Formation. In Biotechnological Applications of Quorum Sensing Inhibitors, (Ed. V. C. Kalia), Springer, Singapore, 2018, 3-21.

(35) Chouhan, S.; Sharma, K.; Guleria, S. Antimicrobial Activity of Some Essential Oils Present Status and Future Perspectives. Medicines 2017, 4, 1-21.

(36) Lv, F.; Liang, H.; Yuan, Q.; Li, C. In Vitro Antimicrobial Effects and Mechanism of Action of Selected Plant Essential Oil Combinations Against Four Food-Related Microorganisms. Food Res. Int. 2011, 44, 3057-3064.

(37) Ciandrini, E.; Campana, R.; Federici, S.; Manti, A.; Battistelli, M.; Falcieri, E.; Papa, S.; Baffone, W. In Vitro Activity of Carvacrol against Titanium-Adherent Oral Biofilms and Planktonic Cultures. Clin. Oral Investig. 2014, 18, 2001-2013.

(38) Alexander, T. E.; Lozeau, L. D.; Camesano, T. A. QCM-D Characterization of TimeDependence of Bacterial Adhesion. Cell Surf. 2019, 5, 100024-100031.

(39) Poitras, C.; Tufenkji, N. QCM-D-Based Biosensor for E. coli O157 : H7 Highlighting the 
Relevance of the Dissipation Slope as a Transduction Signal Biosens. Bioelectron. 2009, 24, 2137-2142.

(40) Kahl, B. C.; Becker, K.; Löffle, B. Clinical Significance and Pathogenesis of Staphylococcal Small Colony Variants in Persistent Infections. Clin. Microbiol. Rev. 2016, 29, 401-427.

(41) Williamson, D. A.; Carter, G. P.; Howden, B. P. Current and Emerging Topical Antibacterials and Antiseptics: Agents, Action, and Resistance Patterns. Clin. Microbiol. Rev. 2017, 30, 827-860.

(42) Baptista, P. V.; Mccusker, M. P.; Carvalho, A.; Ferreira, D. A.; Mohan, N. M.; Martins, M.; Fernandes, A. R. Nano-Strategies to Fight Multidrug Resistant Bacteria -A Battle of the Titans. Front. Microbiol. 2018, 9, 1-26.

(43) Landis, R. F.; Li, C.H.; Gupta, A.; Lee, Y.W.; Yazdani, M.; Ngernyuang, N.; Altinbasak, I.; Sanaa, M.; Khichi, M. A. S.; Sanyal, A.; Rotello, V. M. Biodegradable Nanocomposite Antimicrobials for the Eradication of Multidrug-Resistant Bacterial Biofilms Without Accumulated Resistance. J. Am. Chem. Soc. 2018, 140, 6176-6182.

(44) Merino, N.; Berdejo, D.; Bento, R.; Salman, H.; Lanz, M.; Maggi, F.; Sánchez-Gómez, S.; García-Gonzalo, D.; Pagán, R. Antimicrobial Efficacy of Thymbra Capitata (L.) Cav. Essential Oil Loaded in Self-Assembled Zein Nanoparticles in Combination with Heat. Ind. Crops Prod. 2019, 133, 98-104. 


\section{Table of Contents graphic}

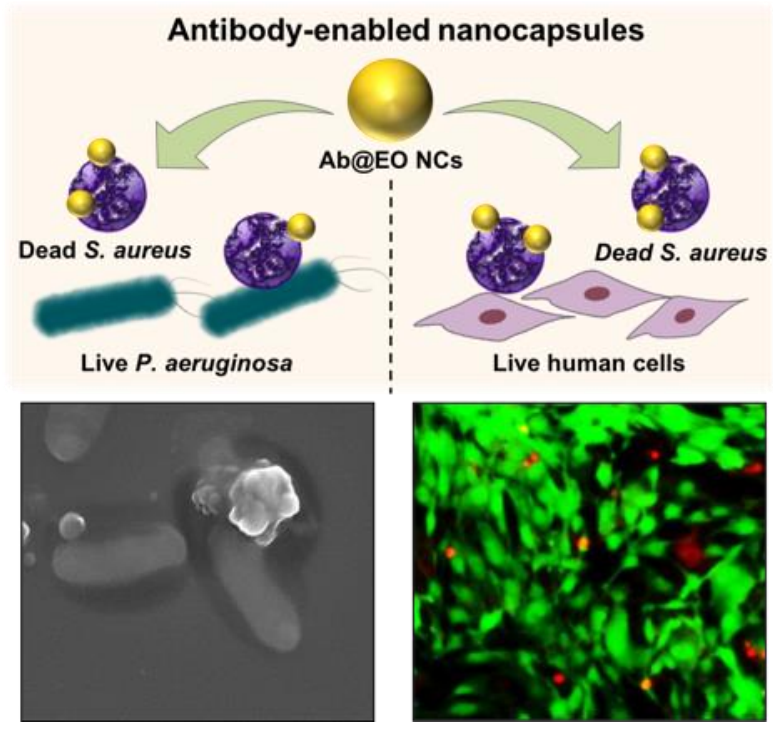

